\title{
BONES WITH BIOCERAMICS
}

\author{
Wijianto \\ Mechanical Engineering Dept. \\ Muhammadiyah University of Surakarta \\ Jl. A. Yani Tromol Pos I Pabelan Kartasura Sukoharjo \\ E-mail:wijianto@ums.ac.id
}

\begin{abstract}
This paper discuss about ceramics in application as bone implant. Bioceramics for instance Hydroxyapatite, usually is abbreviated with HA or HAp, is a mineral that is very good physical properties as bone replacement in human body. To produce Hydroxyapatite, coating process is used which have good potential as they can exploit the biocompatible and bone bonding properties of the ceramic. There are many advantages and disadvantages of bioceramics as bone implant. Advantages of hydroxyapatite as bone implant are rapidly integrated into the human body, and is most interesting property that will bond to bone forming indistinguishable unions. On contrary, disadvantages of hydroxyapatite as bone implant are poor mechanical properties (in particular fatigue properties) mean that hydroxyapatite cannot be used in bulk form for load bearing applications such as orthopaedics and poor adhesion between the calcium phosphate coating and the material implant will occur.
\end{abstract}

\section{Key words: Bioceramics, Hidoxyapatite (HA), Bone Implant}

\section{INTRODUCTION}

Ceramics are one of the most important materials in human activity in everyday. Ceramics is often broadly defined as any inorganic nonmetallic material. The most common of terrestrial materials, ceramics in the form of sand and clay have been used for many thousands of years to make brick, pottery, and art ware. Modern structural ceramics bear little resemblance to these "traditional" materials; they are made from extremely pure, microscopic powders which are consolidated at high temperatures to yield a dense, durable structure.

In the sciences and technologies area, ceramics often very important for example, the incredible growth in wireless communications would not have been possible without the miniaturization permitted by oxide ceramic microwave filters and resonators. Scanningtunneling and atomic-force microscopy, medical ultrasound technology, auto focus cameras, and the vision-correction system of the Hubble Telescope all rely on piezoelectric ceramics. (Chiang and Jacus, 1999)

In the medical sector, repair, reconstruction, and replacement of the hard tissues of the body, bone and teeth, are largely possible today due to the development of bioceramics.

As can be seen in the figure 1 above, that the global market of bioceramics, specially for bone substitute always increase in every year, which this is given information that requirement of bioceramics is very high.

As can be seen in the figure 2, that ceramicimplant sees so much like the real thing, which they could actually melt with living bone. 